\title{
Economic Interdependence and Integration in the Northeast Asia
}

\author{
Kyung Hee University Jung Mo Kang \\ Korea Institute of Industrial Economics and Technology Hwa Seob Kim
}

JEL classification : 420

key words : economic integration in Northeast Asia, gravity model.

The purposes of this paper are: a) to examine the existence of the functional economic integration in Northeast Asia (NEA) by using the gravity model, b) to measure the degree of contribution to the functional integration of NEA, and c) to propose the construction of circulation mechanism for resources and commodities that links NEA region.

According to gravity estimate for trade among NEA countries, only in 1993 does it attain a statistically significant level of .55 , rising to .76 in 1995 . The parameter estimate for 1995 is exp $(.76)=2.13$ with 1 percent significance level, meaning that the functional integration in NEA was in existence and increased intra-regional trade by $113 \%$. In other words, two countries in NEA trade 2.13 times more, after holding constant for GDP, per capita GDP, proximity and the other gravity variables, than two otherwise-similar countries. Our results also indicate that the degree of contribution by China, Taiwan and Hong Kong to the functional economic integration is higher than that by Korea and Japan.

The rapidly rising and relatively large effect of functional regional integration without institutional regional integration is due to China's increasing role in regional trade within NEA. After adopting an open-door policy in 1978, China increased indirect trade with South Korea and Taiwan, through Hong Kong and Japan, in the 1980s. Then direct trade with them rapidly increased in the 1990s due to the formal diplomatic relationship in 1992. This functional integration effect will grow as China's economy and foreign trade increases.

The reasons for closer economic cooperation in the NEA are deepening economic interdependence among the NEA countries (especially Korea, Japan and China), the prevention of overlap-

\footnotetext{
E-mail : jmkang@nms.kyunghee.ac.kr

E-mail : khwas@kiet.re.kr
} 
ping investment in major industries, and the growing number of fields requiring the coordination of interests such as fishing activity rights and the problem of trans-boundary pollution.

The reasons for the absence of a major regional integration arrangement in NEA are: a) High barriers to economic integration make institutional integration ineffective; b) NEA economies have been competitive enough against the rest of the world on an individual basis. However, the emergence of new regionalism poses a threat to NEA economies by making the EU and NAFTA economies more competitive vis-a-vis NEA economies in sectors which are losing their competitiveness. As defensive measures, NEA has strengthened the multilateral trading system by actively contributing to the establishment of the WTO, and promoted its own version of open regionalism which induces trade and investment by facilitating as well as liberalizing trade.

However, since NEA countries feel threatened by new regionalism, they need to seek institutional integration. An important precondition is full integration of the two Koreas into one economy, whether through unification or an equivalent process.

So far, the following schemes were proposed for economic cooperation in NEA: a) the Tumen River area development program, b) utilization of Trans-Siberia Railway, Trans-China Railway, Trans-Korea Railway, Trans-Asian Railway, and so on, c) laying of underground pipelines to transport Russia's abundant crude oil and natural gas, d) promotion of tourism development projects along East Sea rim, e) expansion of sea transport network, and joint development of resources, and f) establishment of Northeast Asian Development Bank and Asian Monetary Fund.

However, due to the difficulty of forming a traditional type of economic integration, NEA countries should seek some other devise to promote regional economic integration as an alternative like the Council for Northeast Asian Economic Cooperation (CNAEC) to discuss comprehensive economic cooperation and major economic issues among NEA countries.

We need to remove infrastructural barriers to efficiently compete with other continent-sized blocs. The incentives for systematizing international physical distribution include a) providing higher quality of physical distribution among countries, b) minimizing the costs of international physical distribution, c) minimizing external diseconomies, and d) strengthening export competitiveness. 